\title{
Noradrenaline-Induced Smooth Muscle Relaxation in the Specific Region of Canine Facial Vein: Implications for Facial and Cranial Circulation
}

\author{
Masayuki HAYASHI, Fumitaka IKOMI, and Toshio OHHASHI \\ Department of Physiology, Shinshu University School of Medicine, Matsumoto, 390-8621 Japan
}

\begin{abstract}
This study was performed to investigate the heterogeneity of physiological and pharmacological properties in segments of the facial veins with special reference to selective brain cooling. Canine facial veins were isolated and the isometric tension of each segment was measured using the organ bath technique. Vessels in the segments of the facial veins that run opposite to the buccal cavity automatically produced myogenic tone and tended to show spontaneous contractions, but vessels in other segments did not. When no contractile agent was used for precontraction, noradrenaline and adrenaline produced dosedependent relaxations in the former venous segments, but contractions in the latter ones. A Schild plot analysis for metoprolol against denopamine and for ICl118,551 against salbutamol
\end{abstract}

showed that the venous segments running opposite the buccal cavity contained both $\beta_{1}$ - and $\beta_{2}$-adrenoceptors, but the other venous segments contained only $\beta_{2}$-adrenoceptors. Electrical field stimulation-induced tetrodotoxin-sensitive relaxations in the former venous segments were diminished by pretreatment with metoprolol, but not with ICl118,551, indicating that the electrical stimulation-induced relaxation may be related to the activation of $\beta_{1}$-adrenoceptors in the venous smooth muscles. In conclusion, the heterogeneity of the functional properties, especially in the distribution of $\beta$-adrenoceptors, in different segments of canine facial veins was observed in the present study, and autoregulatory mechanisms, humoral mechanisms, and neural mechanisms were suggested to affect cranial venous drainage.

Key words: venous smooth muscle, spontaneous rhythmic contraction, $\beta$-adrenoceptors, sympathetic innervation, cranial circulation.

$\mathrm{T}$ that communicates with the cavernous sinus through the ophthalmic vein and orbital venous plexus [1]. This network is known to deliver cold venous blood from the nasal mucosa to the cavernous sinus, which is located at the bottom of the brain [2]. In some species, including humans, dogs [1], and reindeer [2], the carotid artery runs within the cavernous sinus, in which heat may be exchanged with warm blood ascending in the carotid artery. This mechanism has been directly demonstrated to mediate a selective cooling of the brain in reindeer [2].

Venous blood from nasal mucosa passes through not only the cavernous sinus, but also the buccal part of the facial vein. The distribution of blood flow in this venous network will be determined by the relative resistances in each segment of the network. Marked heterogeneity in functional and morphological properties has been demonstrated in different segments of the veins [3]. For example, the buccal segment of the facial vein shows unique characteristics, such as stretch- and flow-dependent temperature-sensitive intrinsic myogenic tone [4, 5], noradrenaline-induced vasorelaxation, electric field stimulationinduced vasorelaxation, a thick vascular wall accompany- ing the relatively wide lumen, and a dense innervation of adrenergic and peptidergic fibers extending throughout the thickness of the vessel wall $[3,6]$. Under heat stress, augmented nasal mucosal venous drainage, increased temperature of the buccal segment of the facial vein, and a suppression of the activity of sympathetic nerves together may cause constriction of this segment of the vein. Thus the constriction of this segment, which acts as a "facial venous sphincter," may affect the distribution of blood flow through the venous network and contribute to the enhancement of selective brain cooling during heat stress. The physiological and pharmacological functional properties of each segment of facial veins, however, have not been well elucidated.

In this study, we first attempted to evaluate the mechanical properties of the veins, such as myogenic tone and spontaneous contractions; second, we attempted to evaluate the effects of catecholamines and other vasoactive substances on the venous smooth muscles; and third, we attempted to pharmacologically classify $\beta$-adrenoceptor subtypes in the segments of facial veins. Moreover, the current study was designed to characterize the mode of action of autonomic innervation in the isolated venous seg-

Received on Aug 20, 2006; accepted on Oct 6, 2006; released online on Oct 12, 2006; doi:10.2170/physiolsci.RP009706 Correspondence should be addressed to: Toshio Ohhashi, Department of Physiology, Shinshu University School of Medicine, 3-1-1 Asahi, Matsumoto, 390-8621 Japan. Tel: +81-263-37-2595, Fax: +81-263-36-5149, E-mail: ohhashi@sch.md.shinshu-u.ac.jp 
ments. The results of this study may provide further understanding regarding the regulation of cranial venous blood drainage with special reference to selective brain cooling.

\section{MATERIALS AND METHODS}

Tissue preparation. Forty-two mongrel dogs of both sexes, weighing $8.2 \pm 2.7 \mathrm{~kg}$ (mean $\pm \mathrm{SD}$ ), were anesthetized with sodium pentobarbital $(25 \mathrm{mg} / \mathrm{kg}$ i.v.) and exsanguinated via the femoral veins. Facial veins were rapidly dissected out and cleaned of surrounding tissues. Preparations were dissected out from each segment of the veins, i.e., the mandibular facial vein (MFV), the proximal part of the buccal facial vein (pBFV), the central part of the buccal facial vein (cBFV), the proximal part of the deep facial vein (pDFV), the distal part of the deep facial vein (dDFV), the distal part of the buccal facial vein (dBFV), the dorsal nasal vein (DNV), and the angularis oculi vein (AOV) (total 194 preparations) (Fig. 1). Ring preparations $4 \mathrm{~mm}$ wide were cut from the segments. All animals were treated in accordance with the guiding principles of the Physiological Society of Japan.

Measurement of mechanical activity. Two tungsten wires ( $100 \mu \mathrm{m}$ in diameter) were run through the lumen of the venous segment. The upper end of the segment was connected to the lever of a force-displacement transducer (Shinko Tsushin UL10, Tokyo, Japan), and the lower end was fixed to the bottom of the bath. The isometric tension detected by the transducer was amplified and recorded on a direct-writing oscillograph (Sanei Sokki, 8K, Tokyo, Japan). Each segment was suspended in a $10 \mathrm{ml}$ organ bath and perfused at a constant rate of $4 \mathrm{ml} / \mathrm{min}$ with Krebs-bicarbonate solution, which was maintained at $37.0 \pm 0.5^{\circ} \mathrm{C}$ and aerated with $95 \% \mathrm{O}_{2}$ and $5 \% \mathrm{CO}_{2}$ to give $\mathrm{pH}$ 7.4. The composition of the Krebs solution was as follows (in mM): $\mathrm{NaCl}, 120.0 ; \mathrm{KCl}, 5.9 ; \mathrm{NaHCO}_{3}, 25.0 ; \mathrm{NaH}_{2} \mathrm{PO}_{4}, 1.2$; $\mathrm{CaCl}_{2}, 2.5 ; \mathrm{MgCl}_{2}, 1.2$; and glucose, 5.5. The resting tension of each segment was set at $0.5 \mathrm{~g}$, which was optimal for inducing maximal contraction developed by a high potassium ( $80 \mathrm{mM}$ ) Krebs-bicarbonate solution. A high potassium Krebs-bicarbonate solution was prepared by replacing part of the $\mathrm{NaCl}$ with an equimolar amount of $\mathrm{KCl}$.

All venous segments were allowed to equilibrate for 60 $\min$ in the oxygenated bathing medium before the start of the experiment. After this equilibration period, the strength and frequency of the spontaneous contractions were measured. The following protocols were then carried out.

\section{Experimental protocols}

Protocol 1: Contractile and relaxant responses of facial venous smooth muscles. After $80 \mathrm{mM} \mathrm{K}^{+}$Krebs-bicarbonate solution-induced contraction had been obtained, cumulative concentration-response curves for noradrena- line (NA), adrenaline (Adr), prostaglandin $\mathrm{F}_{2 \alpha}\left(\mathrm{PG} \mathrm{F}_{2 \alpha}\right)$, 5-hydroxytryptamine (5-HT), and histamine (His) were constructed in a randomized order in each preparation, using serial tenfold dilutions of each agent, as soon as a steady response to the previous administration had been achieved. Cumulative concentration-response curves for isoprenaline (ISP), acetylcholine (ACh), sodium nitroprusside (SNP), His, adenosine (ADO), adenosine triphosphate (ATP), and adenosine diphosphate (ADP) were similarly constructed in the venous rings, which had been contracted with $3 \times 10^{-6}-10^{-5} \mathrm{M} 5$-HT. The precontraction in each venous ring was $\sim 60 \%$ of the contraction induced by myogenic tone plus $80 \mathrm{mM} \mathrm{K}^{+}$Krebs-bicarbonate solution.

As shown in Fig. 2, passive tension was determined as the maximal relaxation level of each ring preparation, which had been achieved at rest or during drug-induced relaxant responses. Myogenic tone was measured just before applying $80 \mathrm{mM} \mathrm{K}^{+}$Krebs-bicarbonate solution, and precontraction was defined as myogenic tone plus 5-HTinduced contraction. The degree of contraction induced by each drug was expressed as a percentage of the $80 \mathrm{mM} \mathrm{K}^{+}$ Krebs-bicarbonate solution-induced contraction, and the degree of relaxation was expressed as a percentage of the precontraction.

Protocol 2: Classification of $\beta$-adrenoceptor subtypes in $p B F V, c B F V, p D F V$, and $A O V$. In this protocol, $\mathrm{pBFV}$, cBFV, and pDFV were used with no discrimination because no significant difference in contractile and relaxant responses was observed among these veins in protocol 1 . Venous ring preparations of $\mathrm{pBFV}, \mathrm{cBFV}, \mathrm{pDFV}$, and $\mathrm{AOV}$ were precontracted by perfusion of the Krebs-bicarbonate solution containing $3 \times 10^{-6}-10^{-5} \mathrm{M} 5-\mathrm{HT}$, which resulted in $\sim 60 \%$ of the contraction induced by the $80 \mathrm{mM}$ $\mathrm{K}^{+}$Krebs-bicarbonate solution. After the precontraction reached a plateau, cumulative concentration-response curves for $\beta$-adrenoceptor agonists, denopamine, a selective $\beta_{1}$-adrenoceptor agonist, and salbutamol, a selective $\beta_{2}$-adrenoceptor agonist, were obtained in each venous segment. The extent of relaxation was expressed as a percentage of the precontraction. In some experiments, selective $\beta$-antagonists, metoprolol $\left(10^{-8} \mathrm{M}, 10^{-7} \mathrm{M}, 10^{-6} \mathrm{M}, \beta_{1}\right)$ and ICI118,551 $\left(10^{-8} \mathrm{M}, 10^{-7} \mathrm{M}, 10^{-6} \mathrm{M}, \beta_{2}\right)$ were dissolved in the oxygenated Krebs-bicarbonate solution and perfused at least $20 \mathrm{~min}$ before the concentration-response curves for denopamine or salbutamol were determined.

A linear relationship was obtained when the molar concentration of the $\beta$-antagonists was plotted on the abscissa on a logarithmic scale against the dose ratio of the corresponding $\beta$-agonist minus unity on the ordinate on a logarithmic scale. The slope and $\mathrm{pA}_{2}$ values for the $\beta$-antagonists, i.e., the antagonist concentration at which the dose ratio is equal to 2, were calculated as described by Arunlakshana and Schild (1959) to compare the blocking potency of the antagonists. 
Protocol 3: Effects of electrical field stimulation on mechanical activity in $A O V$ and $c B F V$. Electrical field stimulation was delivered in the AOV and $\mathrm{cBFV}$ via platinum electrodes at the top and bottom of the organ bath from a Square One modular stimulator (SEN 710, Isolator SS102J, Nihon Koden, Tokyo, Japan) without touching preparations. The adjustment of electrical stimulation was monitored with an oscilloscope (VC4065, Hitachi, Tokyo, Japan). The segments were stimulated with $15 \mathrm{~s}$ trains of pulses at a nominal voltage of $25 \mathrm{~V}$ and pulse width of $0.1 \mathrm{~ms}$.

After $80 \mathrm{mM} \mathrm{K}{ }^{+}$Krebs-bicarbonate solution-induced contraction had been obtained, the isometric tension was measured. The frequency of the stimulation was shifted in steps from 0.5 to $1,2,4,8,16$, and $32 \mathrm{~Hz}$ with an interval of $2 \mathrm{~min}$. Then the bath solution was changed to Krebs-bicarbonate solution containing tetrodotoxin (TTX) $\left(10^{-7}\right.$ $\mathrm{M})$, and the response to the same stimulation was again assessed after an equilibration period of $30 \mathrm{~min}$.

In other cBFV segments, 5 repeated stimulations with an interval of $2 \mathrm{~min}$ were performed. Then phentolamine $\left(10^{-6} \mathrm{M}\right)$, phentolamine $\left(10^{-6} \mathrm{M}\right)+\operatorname{ICI} 118,551\left(10^{-8} \mathrm{M}\right)$, and phentolamine $\left(10^{-6} \mathrm{M}\right)+\mathrm{ICI} 118,551\left(10^{-8} \mathrm{M}\right)+$ metoprolol $\left(10^{-7} \mathrm{M}\right)$ were dissolved in the Krebs-bicarbonate solution and perfused at least $30 \mathrm{~min}$ before the stimulation-induced responses were observed in the order described at the stimulation frequency of $4 \mathrm{~Hz}$. Phentolamine $\left(10^{-6} \mathrm{M}\right)$, phentolamine $\left(10^{-6} \mathrm{M}\right)+$ metoprolol $\left(10^{-7}\right.$ $\mathrm{M})$, and phentolamine $\left(10^{-6} \mathrm{M}\right)+$ metoprolol $\left(10^{-7} \mathrm{M}\right)+$ ICI118,551 $\left(10^{-8} \mathrm{M}\right)$ were also administered at a frequency of $8 \mathrm{~Hz}$. The degree of the responses was expressed as a percentage of the electrical stimulation-induced relax- ation without drugs in each preparation.

Drugs. We used the following drugs: adenosine, adenosine 5 '-diphosphate sodium salt, adenosine 5'-triphosphate disodium salt, 1-adrenaline bitartrate, 1-noradrenaline bitartrate, 5-hydroxytryptamine creatine sulfate, salbutamol hemisulfate, tetrodotoxin (Sigma, St. Louis, MO); prostaglandin $\mathrm{F}_{2 \alpha}$ (Ono Yakuhin, Osaka, Japan); denopamine (Tanabe, Tokyo, Japan); acetylcholine chloride, 1-isoprenaline hydrochloride (Nikken Kagaku, Tokyo, Japan); metoprolol tartrate, phentolamine mesylate (CibaGeigy, Basel, Switzerland); and ICI118,551 (erythro-dl-1(7-methylindan-4-yloxy)-3-(isopropylaminobutan-2-ol hydrochloride) (Imperial Chemical Industries, Wilmslow, Cheshire, UK).

Statistics. All results are expressed as the mean \pm SEM unless otherwise indicated. The $\mathrm{pD}_{2}$ was calculated as $-\log \mathrm{ED}_{50}$ in which $\mathrm{ED}_{50}$ is the concentration of agonist causing $50 \%$ of maximum response. A one-way analysis of variance (ANOVA) followed by the Fisher's protected least significant difference (PLSD) test was used to test for statistical significance between groups. The differences between groups were considered significant at $p<0.05$.

\section{RESULTS}

\section{Spontaneous activity of the venous smooth muscle cells in the segments of canine facial veins}

Spontaneous rhythmic contractions were observed in all $\mathrm{pBFV}$ and $\mathrm{cBFV}$ preparations, and in $54 \%$ of $\mathrm{pDFV}$ preparations (Fig. 1, B, C, and D and Table 1). On the other hand, spontaneous rhythmic contractions were not observed in the $\mathrm{dBFV}, \mathrm{DNV}$, or AOV and were observed in

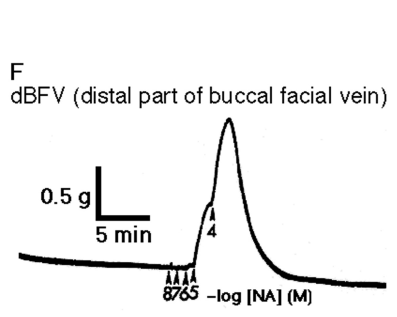

EDFV (distal part of deep facial vein)

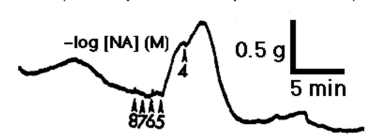

D

pDFV (proximal part of deep facial vein)

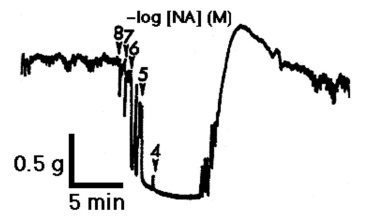

GNV (dorsal nasal vein)
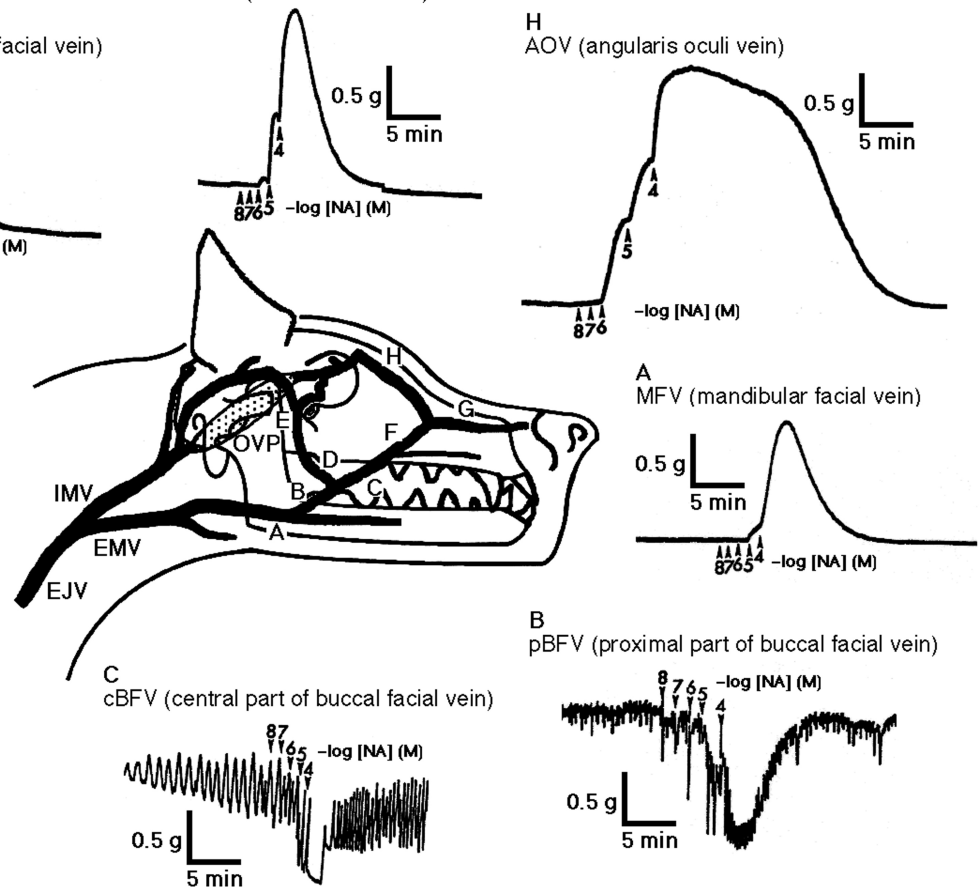

Fig. 1. Diagrammatic anatomy of canine facial venous network and related veins (center) and representative recordings of the effects of noradrenaline (NA) in each segment of the vessels $(\mathbf{A}$ to H). EJV, external jugular vein. IMV, internal maxillary vein. EMV, external maxillary vein. OVP, orbital venous plexus. 
Table 1. Spontaneous contraction of the isolated canine facial veins in each region.

\begin{tabular}{|c|c|c|c|c|c|c|}
\hline Region & $n$ & $\begin{array}{l}\text { Number } \\
\text { spontan }\end{array}$ & $\begin{array}{l}\text { rcentage of } \\
\text { contractile } \\
\text { ls }\end{array}$ & Strength $(\mathrm{g})$ & Frequency $\left(\min ^{-1}\right)$ & $\begin{array}{c}80 \mathrm{mM} \mathrm{K}^{+} \text {-induced } \\
\text { contraction }(\mathrm{g})\end{array}$ \\
\hline MFV & 8 & 1 & $13 \%$ & 0.25 & 6.0 & $2.7 \pm 0.6$ \\
\hline pBFV & 20 & 20 & $100 \%$ & $0.34 \pm 0.05$ & $6.1 \pm 1.0$ & $1.4 \pm 0.2$ \\
\hline cBFV & 9 & 9 & $100 \%$ & $0.23 \pm 0.04$ & $5.7 \pm 0.9$ & $1.3 \pm 0.2$ \\
\hline pDFV & 13 & 7 & $54 \%$ & $0.21 \pm 0.09$ & $5.0 \pm 0.9$ & $1.4 \pm 0.1$ \\
\hline dDFV & 13 & 2 & $15 \%$ & $0.25 \pm 0.05$ & $3.1 \pm 0.1$ & $2.2 \pm 0.3$ \\
\hline $\mathrm{dBFV}$ & 9 & 0 & $0 \%$ & \multicolumn{2}{|c|}{ no spontaneous contraction was observed } & $0.4 \pm 0.1$ \\
\hline DNV & 15 & 0 & $0 \%$ & \multicolumn{2}{|c|}{ no spontaneous contraction was observed } & $2.9 \pm 0.2$ \\
\hline AOV & 21 & 0 & $0 \%$ & \multicolumn{2}{|c|}{ no spontaneous contraction was observed } & $2.7 \pm 0.2$ \\
\hline
\end{tabular}

Values are mean \pm SE. $n$, number of experiments. Each region of facial vein is described in MATERIALS AND METHODS.

Table 2. $80 \mathrm{mM} \mathrm{K}^{+}$-induced contraction, myogenic tone, and $E_{\max }$ and $\mathrm{pD}_{2}$ values of noradrenaline (NA) in the segments of the isolated canine facial veins.

\begin{tabular}{lcccccc}
\hline Region & $n$ & $\begin{array}{c}80 \text { mM K+-induced } \\
\text { contraction }(\mathrm{g})\end{array}$ & Myogenic tone (g) & $\begin{array}{c}\text { NA-induced } \\
\text { response }\end{array}$ & $E_{\max }(\%)$ & $\mathrm{pD}_{2}$ \\
\hline MFV & 4 & $1.9 \pm 0.4$ & 0 & contraction & $>70 \pm 8^{\mathrm{a}}$ & $\mathrm{NC}$ \\
pBFV & 6 & $1.2 \pm 0.2$ & $0.8 \pm 0.2$ & relaxation & $92 \pm 2^{\mathrm{b}}$ & $6.2 \pm 0.3$ \\
cBFV & 4 & $1.3 \pm 0.3$ & $0.9 \pm 0.2$ & relaxation & $90 \pm 4^{\mathrm{b}}$ & $5.7 \pm 0.2$ \\
pDFV & 5 & $1.2 \pm 0.2$ & $1.2 \pm 0.3$ & relaxation & $94 \pm 3^{\mathrm{b}}$ & $5.8 \pm 0.2$ \\
dDFV & 4 & $1.9 \pm 0.2$ & 0 & contraction & $>36 \pm 8^{\mathrm{a}}$ & $\mathrm{NC}$ \\
dBFV & 6 & $0.4 \pm 0.1$ & 0 & contraction & $>141 \pm 7^{\mathrm{a}}$ & $\mathrm{NC}$ \\
DNV & 5 & $2.8 \pm 0.3$ & 0 & contraction & $>51 \pm 13^{\mathrm{a}}$ & $\mathrm{NC}$ \\
AOV & 6 & $2.5 \pm 0.3$ & 0 & contraction & $>78 \pm 11^{\mathrm{a}}$ & $\mathrm{NC}$ \\
\hline
\end{tabular}

Values are mean \pm SE. $n$, number of experiments. a, maximum contractions expressed as a percentage of $80 \mathrm{mM} \mathrm{K}^{+}$-induced contractions. $b$, maximum relaxations expressed as a percentage of myogenic tone. $p D_{2},-\log \left[E D_{50}\right]$ in which $E D_{50}$ is the concentration of NA causing a $50 \%$ of each maximum response. NC, not calculated. Each region of facial vein is described in MATERIALS AND METHODS.

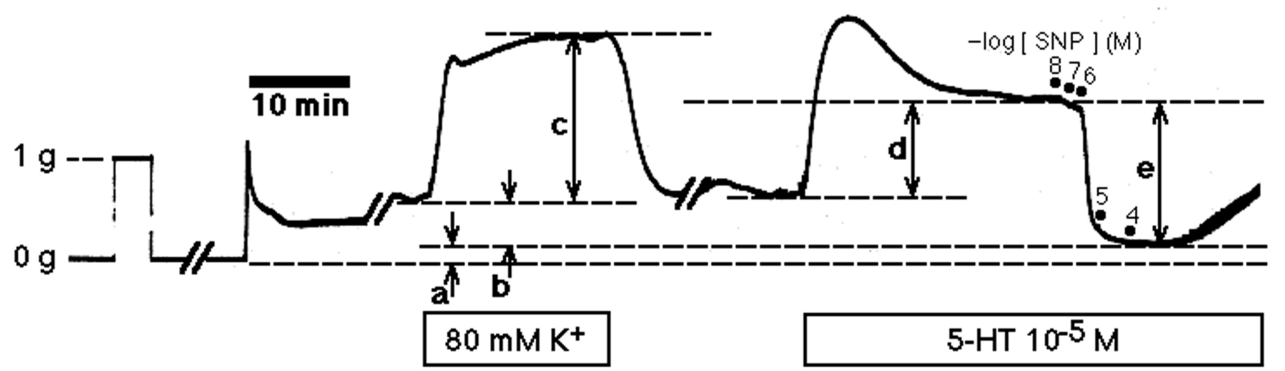

Fig. 2. In vitro recording of a canine facial vein (proximal part of a deep facial vein). SNP, sodium nitroprusside. 5-HT, 5hydroxytryptamine. a, passive tone. b, intrinsic myogenic tone. c, $80 \mathrm{mM} \mathrm{K}^{+}$-induced contraction. d, 5-HT-induced contraction. e, precontraction. only $13 \%$ and $15 \%$ of MFV and dDFV preparations, respectively (Table 1).

Myogenic tone was observed in all pBFV, cBFV, and pDFV preparations (Table 2). No significant differences were observed in the value of developed myogenic tone among these 3 groups. No myogenic tone was observed in the MFV, dDFV, dBFV, DNV, and AOV.

\section{Adrenoceptor agonist-induced contractions and relaxations in the segments of canine facial veins}

Figure 1 shows typical responses of the MFV, pBFV, cBFV, pDFV, dDFV, dBFV, DNV, and AOV to NA. The addition of NA $\left(10^{-8}\right.$ to $\left.10^{-4} \mathrm{M}\right)$ caused concentration-dependent relaxations in the $\operatorname{pBFV}(n=6), \operatorname{cBFV}(n=4)$, and pDFV $(n=5)$ without precontraction other than myogenic tone (Fig. 3 , A and B). No significant differences were observed in the $E_{\max }$ and $\mathrm{pD}_{2}$ of NA-induced relax- ations among these 3 groups (Table 2). On the other hand, NA $\left(10^{-8}\right.$ to $\left.10^{-4} \mathrm{M}\right)$ caused concentration-dependent contractions in the MFV $(n=4), \operatorname{dDFV}(n=4), \operatorname{dBFV}(n=6)$, $\operatorname{DNV}(n=5)$, and AOV $(n=6)$ (Fig. $3, \mathrm{~A}$ and B). The $\mathrm{pD}_{2}$ values of NA in the MFV, dDFV, dBFV, DNV, and AOV were not calculated because up to $10^{-4} \mathrm{M}$ of NA produced no maximum contractions (Fig. 1 and Table 2).

Similar relaxations were induced by $\mathrm{Adr}\left(10^{-8}\right.$ to $10^{-4}$ $\mathrm{M})$ in $\mathrm{pBFV}\left(n=6, E_{\max }=83 \pm 9 \%, 100 \%=1.2 \pm 0.2 \mathrm{~g}\right.$, $\left.\mathrm{pD}_{2}=6.0 \pm 0.2\right)$ and $\mathrm{pDFV}\left(n=5, E_{\max }=73 \pm 12 \%, 100 \%\right.$ $=1.5 \pm 0.4 \mathrm{~g}, \mathrm{pD}_{2}=6.2 \pm 0.3$ ) without precontraction (Fig. $3 \mathrm{C})$. Concentration-dependent contractions were produced by Adr in the MFV $(n=5)$, dDFV $(n=6), \operatorname{dBFV}(n$ $=4), \operatorname{DNV}(n=5)$, and AOV $(n=5)$ (Fig. 3C). Adr did not produce maximum contractions in these venous segments up to $10^{-5} \mathrm{M}$. 
A

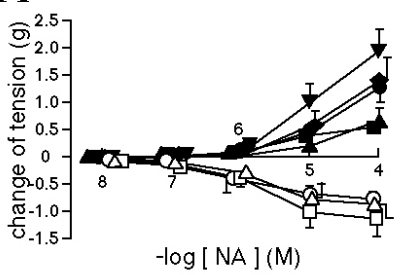

$\mathrm{B}$

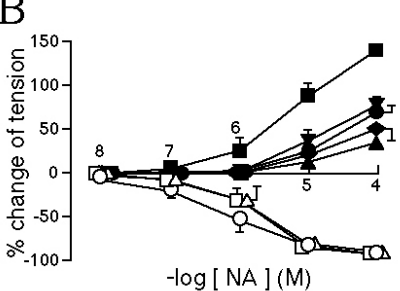

$\mathrm{E}$

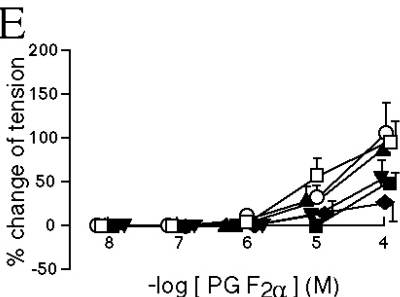

$\mathrm{H}$
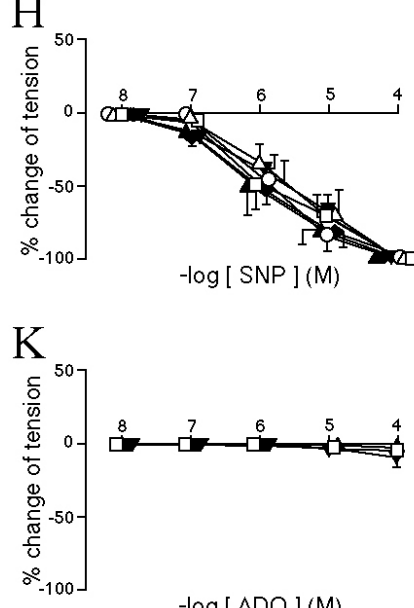

$-\log [\mathrm{ADO}](\mathrm{M})$
- MFV (mandibular facial vein)

0 : pBFV (proximal part of buccal facial vein)

$\triangle$ : CBFV (central part of buccal facial vein)

$\square$ : pDFV (proximal part of deep facial vein)

A : dDFV (distal part of deep facial vein)

: dBFV (distal part of buccal facial vein)

: DNV (dorsal nasal vein)

₹: AOV (angularis oculi vein)
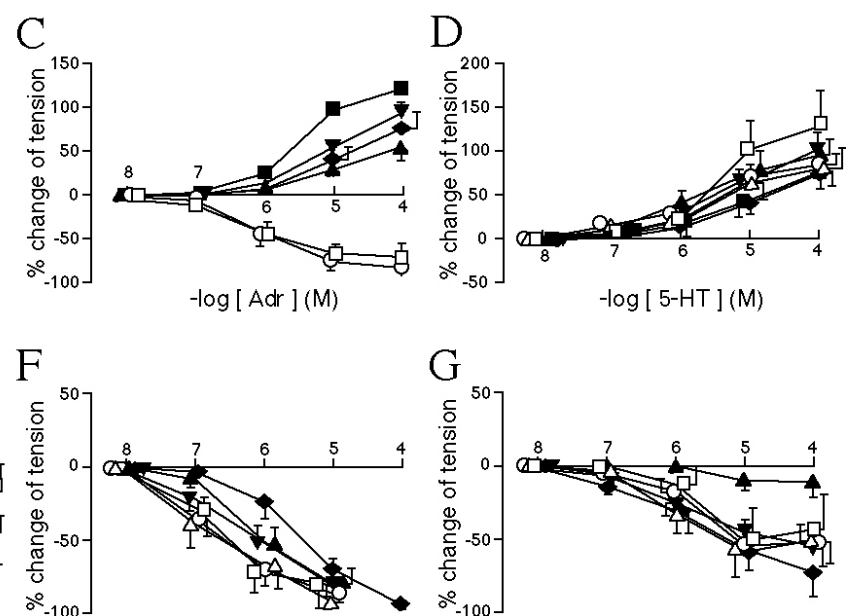

$-\log [$ ISP ] (M)

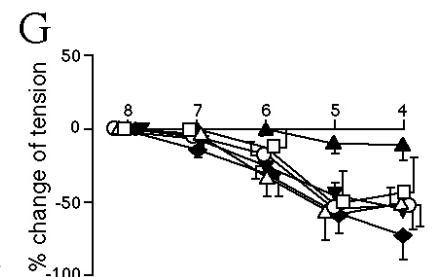

$-\log [\mathrm{ACh}](\mathrm{M})$

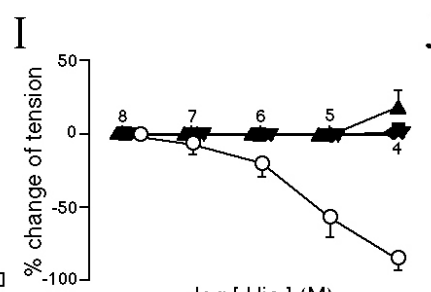

$-\log [\mathrm{His}](\mathrm{M})$

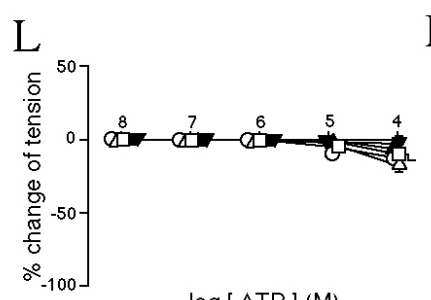

$-\log [$ ATP $](M)$

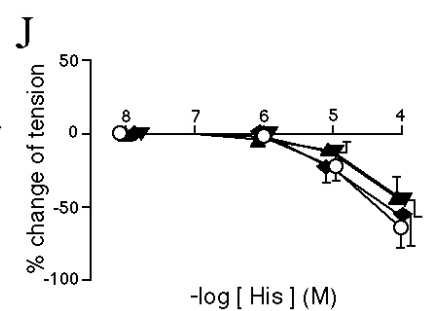

$\mathrm{M}$

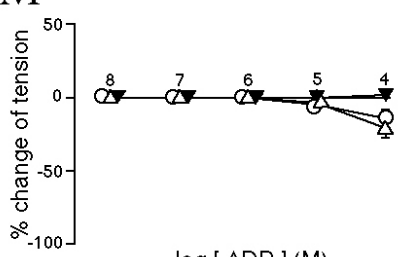

$-\log [\mathrm{ADP}](\mathrm{M})$

Fig. 3. Cumulative dose-response curves to noradrenaline (NA), adrenaline (Adr), 5-hydroxytryptamine (5-HT), prostaglandin $F_{2 \alpha}\left(P G F_{2 \alpha}\right)$, isoprenaline (ISP), acetylcholine (ACh), sodium nitroprusside (SNP), histamine (His), adenosine (ADO), adenosine $5^{\prime}$-triphosphate (ATP), adenosine $5^{\prime}$-diphosphate (ADP) in mandibular facial vein (MFV, solid circles), proximal part of buccal facial vein (pBFV, open circles), central part of buccal facial vein (cBFV, open triangles), proximal part of deep facial vein (pDFV, open squares), distal part of deep facial vein (dDFV, solid triangles), distal part of buccal facial vein (dBFV, solid squares), dorsal nasal vein (DNV, solid diamonds), and angularis oculi vein (AOV, inverted solid triangles) pretreated with 3 $\times 10^{-6}-10^{-5}$ M 5-HT (FGHJKLM) or without any contractile agents (ABCDEI). Preparation numbers in each experiment were described in the text. Each value is presented as a mean \pm SEM (vertical bars). The ordinate shows the isometric tension expressed in gram (A) or expressed as a percent contraction of $80 \mathrm{mM} \mathrm{K}^{+}$-induced contraction and/or percent relaxation of precontraction (B to $\mathbf{M}$ ). The abscissa denotes the molar concentration of agonists on a logarithmic scale.

Figure $3 \mathrm{~F}$ shows the concentration-response curves of ISP $\left(10^{-8}\right.$ to $10^{-5}$ or $\left.10^{-4} \mathrm{M}\right)$ in the $\operatorname{pBFV}(n=6), \operatorname{cBFV}(n$ $=5), \operatorname{pDFV}(n=5), \mathrm{dDFV}(n=4), \mathrm{DNV}(n=4)$, and AOV $(n=6)$ precontracted with $3 \times 10^{-6}$ or $10^{-5}$ M 5 -HT. In these venous segments, ISP produced marked relaxations in a dose-dependent manner $\left(E_{\max }=80-94 \%\right.$, not significant among the groups). The decreasing order of potency for ISP in the relaxant response among the venous segments was as follows $\left(\mathrm{pD}_{2}\right)$ : $\mathrm{pDFV}(6.9 \pm 0.2)=\mathrm{cBFV}$ $(6.7 \pm 0.4)=\operatorname{pBFV}(6.7 \pm 0.2)>\operatorname{AOV}(6.4 \pm 0.3)=\mathrm{dDFV}$ $(6.3 \pm 0.2)>\operatorname{DNV}(5.6 \pm 0.2)$. The $\mathrm{pD}_{2}$ of ISP in the $\mathrm{pBFV}, \mathrm{cBFV}$, and $\mathrm{pDFV}$ were significantly larger than that in the DNV.

\section{Agonist-induced contractile and relaxant responses in the segments of canine facial veins}

5-HT $\left(10^{-8}\right.$ to $\left.10^{-4} \mathrm{M}\right)$ and $\mathrm{PG} \mathrm{F}_{2 \alpha}\left(10^{-8}\right.$ to $\left.10^{-4} \mathrm{M}\right)$ caused dose-dependent contractions in the pBFV $(n=6$ and 6$), \operatorname{cBFV}(n=4,5-\mathrm{HT}), \operatorname{pDFV}(n=5$ and 5$), \operatorname{dDFV}(n$ $=5$ and 4$), \operatorname{dBFV}(n=6$ and 5$), \operatorname{DNV}(n=4$ and 4$)$, and AOV ( $n=5$ and 5). Cumulative concentration-response curves of these agents are summarized in Fig. 3, D and E. None of these agonists showed a plateau of the response at concentrations ranging from $10^{-8}$ to $10^{-4} \mathrm{M}$.

ACh $\left(10^{-8}\right.$ to $\left.10^{-4} \mathrm{M}\right)$ and SNP $\left(10^{-8}\right.$ to $\left.10^{-4} \mathrm{M}\right)$ produced dose-dependent relaxations in venous segments of $\operatorname{pBFV}(n=6$ and 6$), \operatorname{cBFV}(n=5$ and 6$), \operatorname{pDFV}(n=4$ and $5), \operatorname{dDFV}(n=4$ and 4$), \operatorname{DNV}(n=4$ and 4$)$, and $\operatorname{AOV}(n=$ 6 and 6) precontracted with $3 \times 10^{-6}$ or $10^{-5}$ M 5-HT (Fig. 
Table 3. $E_{\max }$ and $\mathrm{pD}_{2}$ values of isoprenaline (ISP) in the segments of the isolated canine facial veins.

\begin{tabular}{llcccc}
\hline Region & $n$ & $\begin{array}{c}80 \mathrm{mM} \mathrm{K}^{+} \text {-induced } \\
\text { contraction }(\mathrm{g})\end{array}$ & Precontraction $(\mathrm{g})$ & $E_{\max }(\%)$ & $\mathrm{pD}_{2}$ \\
\hline pBFV & 5 & $1.4 \pm 0.3$ & $1.1 \pm 0.1$ & $86 \pm 6$ & $6.7 \pm 0.2^{\mathrm{a}}$ \\
CBFV & 5 & $1.3 \pm 0.2$ & $0.8 \pm 0.1$ & $93 \pm 3$ & $6.7 \pm 0.4^{\mathrm{a}}$ \\
pDFV & 8 & $1.4 \pm 0.2$ & $1.2 \pm 0.1$ & $82 \pm 15$ & $6.9 \pm 0.2^{\mathrm{b}}$ \\
dDFV & 6 & $2.3 \pm 0.7$ & $1.6 \pm 0.4$ & $80 \pm 11$ & $6.3 \pm 0.2$ \\
DNV & 5 & $2.6 \pm 0.3$ & $1.3 \pm 0.4$ & $94 \pm 4$ & $5.6 \pm 0.2^{\mathrm{a}, \mathrm{b}}$ \\
AOV & 5 & $2.6 \pm 0.5$ & $1.3 \pm 0.3$ & $83 \pm 8$ & $6.4 \pm 0.3$ \\
\hline
\end{tabular}

Values are mean \pm SE. $n$, number of experiments. $E$, maximum relaxations expressed as a percentage of precontraction, myogenic tone plus $5-\mathrm{HT}\left(3 \times 10^{-6}-10^{-5} \mathrm{M}\right)$-induced contraction. $\mathrm{pD}_{2},-\log \left[\mathrm{ED}_{50}\right]$ in which $\mathrm{ED}_{50}$ is the concentration of ISP causing $50 \%$ of each maximum response. a, $p<0.05$ pBFV vs. DNV and/or cBFV vs. DNV. b, $p<0.01$ pDFV vs. DNV. Each region of facial vein is described in MATERIALS AND METHODS.

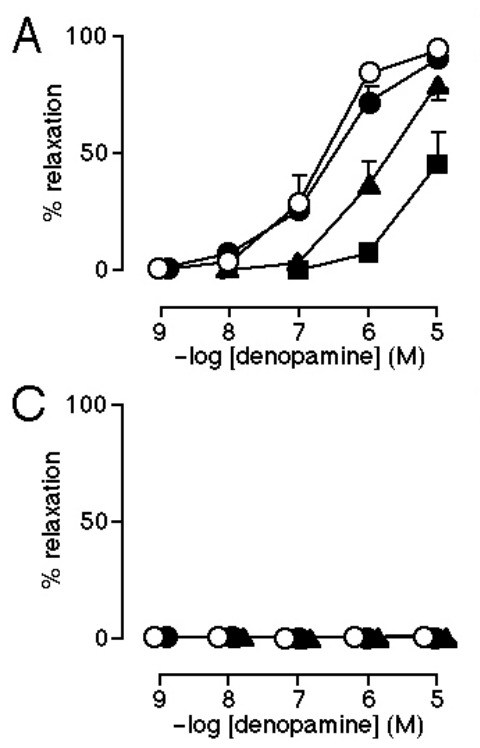

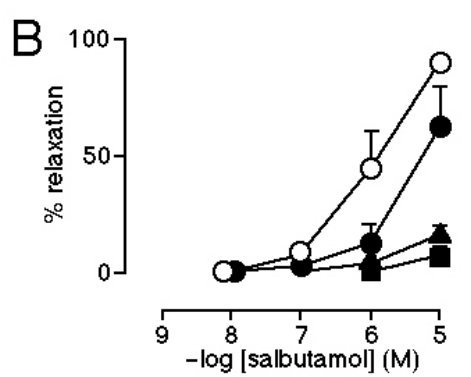

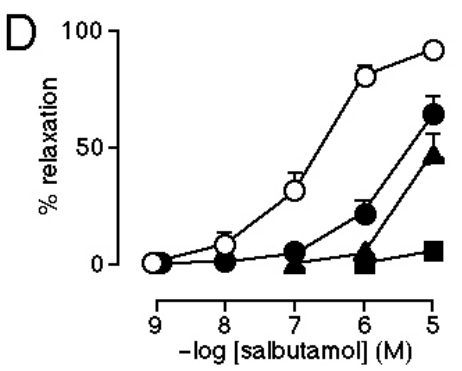

Fig. 4. Effects of metoprolol on relaxation induced by denopamine in pBFV (proximal part of buccal facial vein), cBFV (central part of buccal facial vein), pDFV (proximal part of deep facial vein) $(\mathbf{A}, n=6)$, and AOV (angularis oculi vein) $(C, n=6)$. Effects of $\mathrm{ICl} 118,551$ on relaxation induced by salbutamol in pBFV, cBFV, and pDFV (B, $n=4)$, and AOV (D, $n=$ 4). Open circles, control $(\mathbf{A}, 100 \%=1.9 \pm 0.3 \mathrm{~g} ; \mathbf{B}$, $100 \%=1.6 \pm 0.3 \mathrm{~g} ; \mathbf{C}, 100 \%=1.9 \pm 0.2 \mathrm{~g} ; \mathbf{D}, 100 \%$ $=1.5 \pm 0.3 \mathrm{~g}$ ). Solid circles, $10^{-8} \mathrm{M}$ antagonist. Solid triangles, $10^{-7} \mathrm{M}$ antagonist. Solid squares, $10^{-6} \mathrm{M}$ antagonist. Each value is presented as a mean \pm SEM (vertical bars). In the ordinate, precontraction was taken as $100 \%$. The abscissa denotes the molar concentration of agonists on a logarithmic scale.
3, $\mathrm{G}$ and $\mathrm{H}$ ). The $\mathrm{pD}_{2}$ of $\mathrm{ACh}$ and $\mathrm{SNP}$ in these venous segments was 5.2-5.9 and 5.6-6.1, respectively, and no significant differences were observed among the groups.

His $\left(10^{-8}\right.$ to $\left.10^{-4} \mathrm{M}\right)$-induced responses were evaluated both in venous segments without precontraction and precontracted with $3 \times 10^{-6}$ or $10^{-5}$ M 5-HT (Fig. 3, I and J). In venous segments without precontraction, the $\mathrm{pBFV}(n$ $=6)$ showed dose-dependent relaxation $\left(86 \pm 7 \%\right.$ at $10^{-4}$ $\mathrm{M}, 100 \%=0.9 \pm 0.2 \mathrm{~g})$. On the other hand, the dDFV $(n=$ $4)$, dBFV $(n=6)$, DNV $(n=4)$, and AOV $(n=5)$ demonstrated no contractions or only slight ones at high concentrations of His $\left(\sim 19 \%\right.$ at $\left.10^{-4} \mathrm{M}\right)$ in these segments. When the venous segments of the $\operatorname{pBFV}(n=4), \operatorname{dDFV}(n=3)$, $\operatorname{DNV}(n=3)$, and $\operatorname{AOV}(n=3)$ were precontracted with 3 $\times 10^{-6}$ or $10^{-5}$ M 5-HT, similar dose-relaxant response curves were obtained with His among these segments.

Figure $3 \mathrm{KLM}$ shows dose-response curves of ADO $\left(10^{-8}\right.$ to $\left.10^{-4} \mathrm{M}\right)$, ATP $\left(10^{-8}\right.$ to $\left.10^{-4} \mathrm{M}\right)$, and ADP $\left(10^{-8}\right.$ to $\left.10^{-4} \mathrm{M}\right)$ in the venous segments precontracted with $3 \times 10^{-6}$ or $10^{-5} \mathrm{M} 5$-HT. ADO, ATP, and ADP produced no or only slight relaxation at a high concentration $\left(\sim 18 \%\right.$ at $\left.10^{-4} \mathrm{M}\right)$ in venous segments of the pBFV $(n=6), \operatorname{cBFV}(n=5)$, $\operatorname{pDFV}(n=4), \operatorname{dDFV}(n=4)$, and $\operatorname{AOV}(n=5)(\operatorname{ADO})$; $\operatorname{pBFV}(n=6), \operatorname{cBFV}(n=6), \operatorname{pDFV}(n=4), \operatorname{dDFV}(n=4)$, and $\operatorname{AOV}(n=5)(\mathrm{ATP})$; and $\mathrm{pBFV}(n=4), \operatorname{cBFV}(n=5)$, and $\operatorname{AOV}(n=4)(\mathrm{ADP})$.

\section{$\beta$-adrenoceptors in pBFV, cBFV, pDFV, and AOV}

The addition of denopamine $\left(10^{-9} \mathrm{M}\right.$ to $\left.10^{-5} \mathrm{M}\right)$, a selective $\beta_{1}$-adrenoceptor agonist, caused dose-dependent relaxation in venous segments of the $\mathrm{pBFV}, \mathrm{cBFV}$, and pDFV $(n=6)$, which had been contracted with $10^{-5}$ M 5HT, but not in the precontracted segment of the AOV $(n=$ 6) (Fig. 4, A and C). The relaxant responses of the pBFV, $\mathrm{cBFV}$, and $\mathrm{pDFV}$ to denopamine were suppressed by metoprolol $\left(10^{-8} \mathrm{M}\right.$ to $\left.10^{-6} \mathrm{M}\right)$, a selective $\beta_{1}$-adrenoceptor antagonist, in a dose-dependent manner ( $n=6$, Fig. 4 , A and $\mathrm{C}$ ). The slope and $\mathrm{pA}_{2}$ for this antagonism in the Schild plot analysis are shown in Table 4.

Salbutamol $\left(10^{-9} \mathrm{M}\right.$ to $\left.10^{-5} \mathrm{M}\right)$, a selective $\beta_{2}$-adrenoceptor agonist, produced dose-dependent relaxations in all of the venous segments $(n=4$ for $\mathrm{pBFV}$, cBFV, and pDFV; $n=4$ for AOV) precontracted with $10^{-5} \mathrm{M} 5$-HT (Fig. 4, B and D). ICI118,551 $\left(10^{-8} \mathrm{M}, 10^{-7} \mathrm{M}\right)$, a selective $\beta_{2}$-adrenoceptor antagonist, caused a parallel shift to the right of the concentration-response curve for salbutamol in the pBFV, cBFV,pDFV, and AOV (Fig. 4, B and D). The slope and $\mathrm{pA}_{2}$ for this antagonism in the Schild plot 
Table 4. Evaluation of the interaction of $\beta$-adrenoceptor agonists and antagonists in the segments of the isolated canine facial veins.

\begin{tabular}{clllcr}
\hline \multicolumn{1}{c}{ Region } & Agonist & Antagonist & $n$ & Slope & $\mathrm{pA}_{2}$ \\
\hline \multirow{2}{*}{ pBFV, cBFV, pDFV } & denopamine & metoprolol & 6 & $1.23 \pm 0.13 \mathrm{NS}$ & $7.53 \pm 0.20$ \\
& salbutamol & $\mathrm{ICl} 118,551$ & 4 & $0.90 \pm 0.19 \mathrm{NS}$ & $8.86 \pm 0.54$ \\
\hline \multirow{2}{*}{ AOV } & denopamine & metoprolol & 6 & \multicolumn{2}{c}{ no relaxation was observed } \\
& salbutamol & $\mathrm{ICl} 118,551$ & 4 & $0.84 \pm 0.05 \mathrm{NS}$ & $9.21 \pm 0.17$
\end{tabular}

Values are mean \pm SE. $n$, number of animals. Each region of facial vein is described in MATERIALS AND METHODS. NS, not significantly different from unity.

A

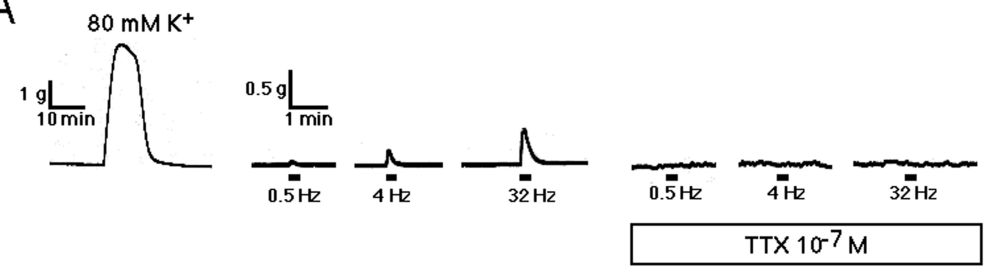

B

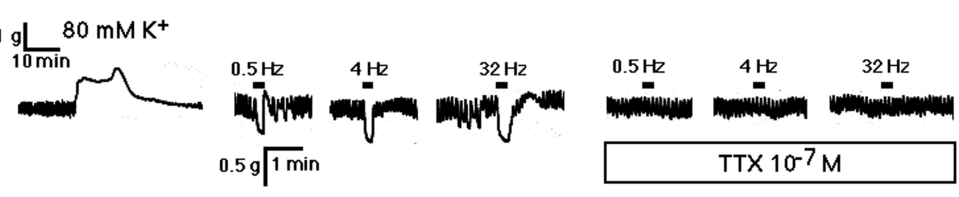

C

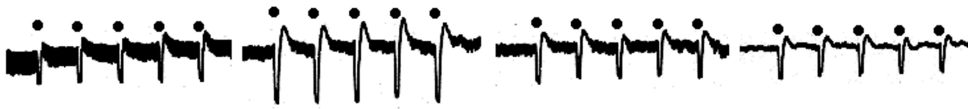

$1 \mathrm { g } \longdiv { 5 \mathrm { min } }$

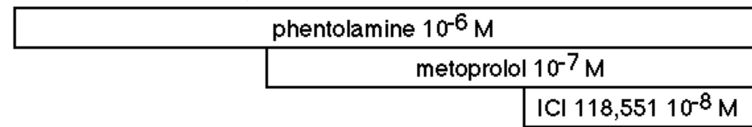

D

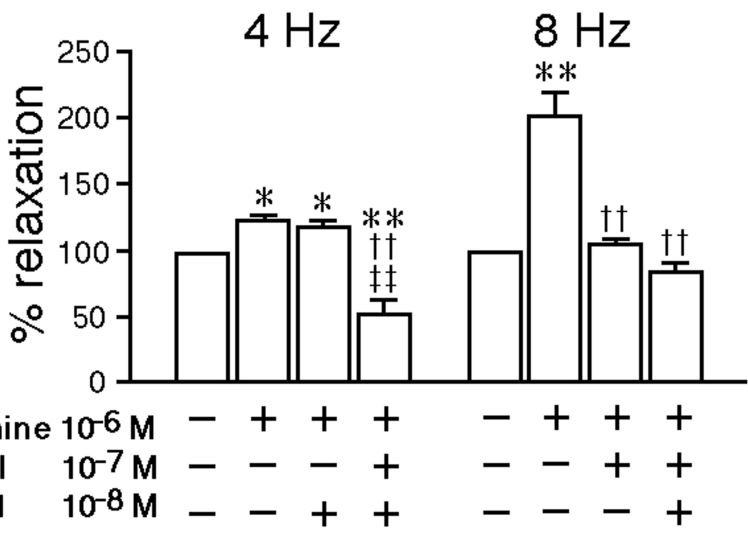

Fig. 5. A: Representative recordings of $80 \mathrm{mM} \mathrm{K}^{+}$ induced contraction and frequency-dependent contractions of AOV (angularis oculi vein) induced by $15 \mathrm{~s}$ trains of electrical field stimulation at $25 \mathrm{~V}$ and $0.1 \mathrm{~ms}$ in pulse width. Pretreatment with $10^{-7}$ $M$ tetrodotoxin abolished the contractions. B: Representative recordings of $80 \mathrm{mM} \mathrm{K}^{+}$-induced contraction and frequency-dependent relaxations of cBFV (central part of buccal facial vein) induced by the similar electrical field stimulation. Pretreatment with $10^{-7} \mathrm{M}$ tetrodotoxin abolished the relaxations. C: Representative recordings of the effects of $10^{-6} \mathrm{M}$ phentolamine, $10^{-7} \mathrm{M}$ metoprolol, and $10^{-8} \mathrm{M} \mathrm{ICl} 118,551$ on the electrical field stimulation-induced relaxations in cBFV at a frequency of $8 \mathrm{~Hz}$. D: Effects of $10^{-6} \mathrm{M}$ phentolamine, $10^{-7} \mathrm{M}$

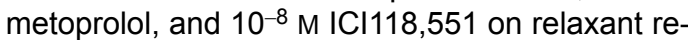
sponses in pBFV (proximal part of buccal facial vein), cBFV, and pDFV (proximal part of deep facial vein) induced by $15 \mathrm{~s}$ trains of electrical field stimulation at 4 or $8 \mathrm{~Hz}, 25 \mathrm{~V}$, and $0.1 \mathrm{~ms}$ in pulse width. The ordinate shows the isometric tension expressed as a percentage of control that was obtained on the absence of the drugs $(100 \%=0.60 \pm$ $0.12 \mathrm{~g}$ at $4 \mathrm{~Hz}, n=4 ; 100 \%=0.81 \pm 0.09 \mathrm{~g}$ at 8 $\mathrm{Hz}, n=4)$. Each value is presented as a mean \pm SEM (vertical bars). ${ }^{*} p<0.05,{ }^{* *} p<0.01$ vs. control. $\dagger \dagger p<0.01$ vs. $10^{-6} \mathrm{M}$ phentolamine. $\ddagger \ddagger p<$ 0.01 vs. $10^{-6} \mathrm{M}$ phentolamine and $10^{-8} \mathrm{M}$ ICl118,551. analysis are shown in Table 4 . In the presence of $10^{-6} \mathrm{M}$ ICI118,551, salbutamol (up to $10^{-5} \mathrm{M}$ ) produced relaxation that was too small to be used in the Schild plot analysis.

\section{Electrical field stimulation-induced mechanical responses of $\mathrm{CBFV}$ and $\mathrm{AOV}$}

Frequency-response relationship. When the frequency of electrical field stimulation was increased from 0.5 to 32 $\mathrm{Hz}$, frequency-dependent contractile and relaxant responses could be obtained in the venous segments of the $\operatorname{AOV}(n=4)$ and cBFV $(n=4)$, respectively (Fig. 5, A and
B). After 30 min of treatment with $10^{-7} \mathrm{M}$ TTX, a sodium channel blocker, the electrical stimulation-induced contractions and relaxations were completely abolished (Fig. 5, A and B).

Effects of phentolamine, ICl118,551, and metoprolol on electrical field stimulation-induced relaxations of cBFV. Figure 5C demonstrates typical traces that show the effects of phentolamine, an $\alpha_{1}$ - and $\alpha_{2}$-adrenoceptor antagonist, ICI118,551, and metoprolol on the electrical field stimulation-induced relaxations at a frequency of $4 \mathrm{~Hz}$ in a segment of canine facial vein. Pretreatment with $10^{-6} \mathrm{M}$ phentolamine caused a significant increase in the electri- 
cal field stimulation-induced relaxation at a frequency of $4 \mathrm{~Hz}$ in $\mathrm{cBFV}(n=4)$ (Fig. 5D). Additional treatment with $10^{-8} \mathrm{M}$ ICI118,551 caused no significant effect on the relaxation. Pretreatment together with $10^{-6} \mathrm{M}$ phentolamine, $10^{-8} \mathrm{M}$ ICI118,551, and $10^{-7} \mathrm{M}$ metoprolol caused a significant decrease in the relaxation of the venous segments. At a frequency of $8 \mathrm{~Hz}, 10^{-6} \mathrm{M}$ phentolamine significantly augmented the relaxant response of the venous segments, and additional treatment with $10^{-7} \mathrm{M}$ metoprolol significantly decreased the relaxation $(n=4)$ (Fig. 5D). No further change was observed by additional treatment with $10^{-8}$ M ICI118,551.

\section{DISCUSSION}

\section{Selective brain cooling}

Venous blood from the nasal mucosa enters both the $\mathrm{dBFV}$ and AOV in the canine cranial drainage system [1]. The dBFV connects with the external jugular vein via the cBFV, pBFV, MFV, and external maxillar vein. On the other hand, the AOV connects with the cavernous sinus via the ophthalmic vein and orbital plexus. The proportion of blood flowing in each direction will be determined by the relative resistance in these pathways. Cooled blood delivered from the nasal mucosa to the cavernous sinus has been directly demonstrated to contribute to thermoregulation of the brain in in vivo experiments in reindeer [2]. When cooled blood flows into the orbital plexuses and the cavernous sinus at the base of the brain, heat might be exchanged with the cerebrospinal fluid. Furthermore, in the cavernous sinus heat would be exchanged with warm blood ascending in the carotid artery. In the canine cranial circulation, similar structures have been observed [1], and these thermoregulatory mechanisms may have a role in brain cooling during thermal stress.

A similar network of branches of the facial veins also exists in human [7] compared with that in dogs [1]. Moreover, Muller-Schweinitzer [8] also reported that the order of potencies of $\alpha$-adrenoceptor agonists, adrenaline and noradrenaline, was similar in human and canine veins. Venous smooth muscle cells of the facial veins in human also produce physiological and pharmacological characteristics similar to those in dogs (as described below), such as intrinsic tone and $\beta$-adrenoceptor-induced relaxation caused by transmural nerve stimulation and NA [9]. Thus our study with canine facial veins may be applicable for understanding human cranial venous circulation.

In general, the smooth muscle layer in veins is thin, and contraction of the smooth muscles is known to produce few or no changes of the resistance of the vein. There are, however, marked regional differences in morphological and mechanical properties in the venous system. A distensibility of venous walls is related to each architecture of collagen fiber, elastic fiber, and smooth muscle cells in the walls [10]. Previous morphological studies demonstrated that a specific area in the buccal region of facial veins has highly thickened media with prominent bands of circulatory smooth muscles in reindeer [2] and desert camel [11]. Further, functional venous occlusion was shown at a segment of the buccal facial veins by cineangiography in reindeer when body temperature was increased [2]. These findings strongly suggest that the contraction of a specific area of the facial veins acts as a sphincter and then produces the redistribution of venous flow in the cranial circulation.

\section{Physiological and pharmacological properties of facial veins}

All canine facial venous segments in buccal part, such as $\mathrm{pBFV}, \mathrm{cBFV}$, and $\mathrm{pDFV}$, which run opposite to the buccal cavity, showed myogenic tone in vitro. Winquist and Bevan (1979) [12] demonstrated that the isolated buccal segment of the rabbit facial vein dramatically developed myogenic tone in response to stretch. This tone was exquisitely sensitive to small changes in temperature in the range of $33.5^{\circ} \mathrm{C}$ to $44.5^{\circ} \mathrm{C}$ [4]. The temperature-induced myogenic tone did not develop at $33.5^{\circ} \mathrm{C}$, but approximately $80 \%$ of the maximum drug-induced tension was achieved at $44.5^{\circ} \mathrm{C}$. Similar temperature-induced myogenic tone has also been observed in desert camels [13]. Thus thermal stress may induce an autoregulation of the cranial circulation, in which a contraction of the facial vein occurs at the buccal segment, and then a larger amount of cooled blood may be delivered from the nasal mucosa to the base of the brain rather than to the external jugular vein. Venous stretch induced by mouth opening may also affect the myogenic tone in the buccal segment of the facial vein.

Besides myogenic tone, spontaneous rhythmic contractions were observed mainly in the buccal part (pBFV, $\mathrm{cBFV}, \mathrm{pDFV}$ ) of the canine facial venous network and related veins. In the DNV of the desert camel, spontaneous contractions were also demonstrated accompanied by myogenic tone [13]. The canine posterior vena cava between the diaphragm and branches of renal veins [14] and the portal vein in the mouse, rat, guinea pig [15], and rabbit [16] are known to make spontaneous rhythmic contractions. These spontaneous contractions of smooth muscle cells in bovine mesenteric lymphatics have been demonstrated to propel lymph fluid to the adjacent lymphangion [17]. The physiological roles of the spontaneous contractions in these segments of the venous system, however, remain to be clarified.

In this study, NA and Adr induced dose-dependent relaxation in the buccal part (pBFV, cBFV, pDFV) only, but contractions in all other segments. In some parts of facial veins, NA-induced relaxation has also been demonstrated in rabbit [3], monkey [18], and man [9]. 5-HT and $\mathrm{PG} \mathrm{F}_{2 \alpha}$ caused dose-dependent contractions in all segments. On the other hand, ACh and His caused dose-dependent re- 
laxations in all segments precontracted with 5-HT. In an earlier study, however, 5-HT caused dose-dependent direct relaxation in rabbit facial veins [19], ACh caused dose-dependent muscarinic $\mathrm{M}_{3}$-receptor-mediated contraction in simian facial veins [20], and His caused dosedependent contraction in rabbit facial veins [3], indicating that there are species differences in the responses to vasoactive agents. ADO, ATP, and ADP mediated no responses or only small ones in the segments. The present results suggested that humoral factors, such as NA, Adr, 5-HT, PG $F_{2 \alpha}, \mathrm{ACh}$, and His have some roles in the distribution of venous flow in the canine cranial venous drainage, but ADO, ATP, and ADP have relatively small roles in the drainage. Especially, NA and Adr reduce venous delivery from the nasal mucosa to the base of the brain via constriction of the MFV and AOV together with dilation of the pBFV and cBFV.

\section{$\beta$-adrenoceptors}

SNP induced dose-dependent relaxations with similar $\mathrm{pD}_{2}$ in all of the venous segments precontracted with 5HT. The $\mathrm{pD}_{2}$ of ISP in the buccal part (pBFV, cBFV, $\mathrm{pD}-$ FV) tended to be larger than in other portions. These findings indicate that the relaxant ability of the smooth muscle cells does not vary significantly among the vessels of these venous segments, but $\beta$-adrenoceptor-induced responses were more potent in the buccal part (pBFV, cBFV, pDFV) than in other segments.

In the buccal part (pBFV, cBFV, pDFV), both denopamine and salbutamol produced dose-dependent relaxations. Metoprolol and ICI118,551 caused a parallel shift to the right of the dose-response curves for denopamine and salbutamol, respectively. The $\mathrm{pA}_{2}$ for metoprolol (7.53) in the buccal part (pBFV, cBFV, pDFV) was similar to that reported for $\beta_{1}$-adrenoceptors in dog coronary arteries (7.48) [21] and bovine mesenteric lymphatics (7.59) [22]. Regarding $\beta_{2}$-adrenoceptor-mediated responses, the $\mathrm{pA}_{2}$ of 8.86 calculated for ICI118,551 in the same segments was similar to that for $\beta_{2}$-adrenoceptors in the guinea pig trachea (8.81) [23] and in canine bronchi (8.91) [24]. These results suggest that venous dilations in these segments are produced via the activation of both $\beta_{1}$ - and $\beta_{2}$-adrenoceptors.

In contrast with the findings for the buccal part (pBFV, cBFV, pDFV), dose-dependent relaxation was caused only by salbutamol in the AOV, not by denopamine. The $\mathrm{pA}_{2}$ for ICI118,551 against salbutamol was 9.21. Thus only $\beta_{2}$-adrenoceptors exist in the AOV and produce venous dilation.

\section{Electrical field stimulation}

In the present experiments, electrical stimulation produced frequency-related contractions in the AOV. On the other hand, the same stimulation induced frequency-related relaxation in the cBFV. These contractions and relax- ations were totally abolished by tetrodotoxin, implying that the responses were neurogenic and not caused by a direct effect on the smooth muscles. Phentolamine significantly augmented the electrical stimulation-induced relaxation in the cBFV. Additional treatment with metoprolol, but not with ICI118,551, significantly reduced the relaxation. The concentration of phentolamine, metoprolol, and ICI118,551 selectively reduce $\alpha-, \beta_{1^{-}}$, and $\beta_{2}$-adrenoceptor-mediated responses, respectively $[22,25]$. These present findings are consistent with the earlier observations that sympathetic nerve stimulation led to vasoconstriction in the AOV through $\alpha$-adrenoceptor stimulation, and the relaxant response to sympathetic nerve stimulation was $\beta_{1}$-adrenoceptor mediated in the buccal part of the rabbit facial vein [26].

\section{Conclusions}

In conclusion, the heterogeneity of the functional properties in different segments of canine facial veins was observed in the present study, and autoregulatory mechanisms that were induced by myogenic activities, humoral mechanisms mediated by vasoactive substances, and neural mechanisms related to the nervous activity of the vessels were suggested to affect cranial venous drainage. Especially, the buccal part (pBFV, cBFV, pDFV), which are located in the wall of the cheek, showed unique properties compared with other segments. These segments showed myogenic tone, spontaneous contractions, NA-induced relaxation, and electrical field stimulation-induced relaxation. Both $\beta_{1}$ - and $\beta_{2}$-adrenoceptors were demonstrated in these segments, and the electrical field stimulation-induced relaxation was suggested to be mediated mainly via $\beta_{1}$-adrenoceptors. These physiological characteristics in the veins may contribute to selective brain cooling during heat stress.

In the future, temperature-dependent changes in the physiological and pharmacological responsiveness in each segment of canine facial veins should be analyzed in detail. The mechanisms of brain cooling during exercise should be also examined because the increase of sympathetic activity may facilitate venous drainage through the buccal part (pBFV, cBFV, pDFV) and decrease venous flow from the nasal mucosa to the cavernous sinus.

The authors thank Professor S. Chiba (Dept. of Pharmacology, Shinshu Univ.) for the kind gift of ICI118,551. This study was supported financially in part by a Grant-in-Aid for scientific research (No. 17639015) from the Japanese Ministry of Education, Culture, Sports, Science and Technology.

\section{REFERENCES}

1. Miller ME. Anatomy of the dog. Philadelphia: W.B.Saunders; 1964.

2. Johnsen HK, Blix AS, Mercer JB, Bolz KD. Selective cooling of the brain in reindeer. Am J Physiol. 1987;253:R848-53.

3. Pegram BL, Bevan RD, Bevan JA. Facial vein in the rabbit. Neurogenic vasodilation mediated by $\beta$-adrenergic receptors. Circ Res. 1976;39:854-60.

4. Winquist RJ, Bevan JA. Temperature sensitivity of tone in the rabbit facial vein: myogenic mechanism for cranial thermoregulation. Science 1980;207:1001-2. 


\section{HAYASHI et al.}

5. Henrion D, Laher I, Bevan JA. Intraluminal flow increases vascular tone and ${ }^{45} \mathrm{Ca}^{2+}$ influx in the rabbit facial vein. Circ Res 1992;71:339-45

6. Johnsen HK, Helle KB, Lundberg JM, Hokfelt T, Folkow LP. Distribution and vasomotor effects of neuropeptides in angular oculi and facial veins of reindeer. Comp Biochem Physiol Comp Physiol. 1992;101:269-76.

7. Pansky B. Review of gross anatomy (5th edition). New York: Macmillan Publishing Co., 1984

8. Muller-Schweinitzer E. On the pharmacology of venous smooth muscle from dog and man. Folia Haematol. 1979;106:690-704

9. Mellander S, Andersson PO, Afzelius LE, Hellstrand P. Neural $\beta$-adrenergic dilatation of the facial vein in man. Possible mechanism in emotional blushing. Acta Physiol Scand. 1982;114:393-9.

10. Ohhashi T, Morimoto-Murase K, Kitoh T. Physiology and functional anatomy of the venous system. In: Hirakawa S, Rothe CF, Shoukas AA, Tyberg JV, editors. Veins: Their functional role in the circulation. Tokyo: Springer-Verlag; 1993. p. 33-47.

11. Bou-Resli MN, Elkhawad AO, Al-Zaid NS. Heterogeneity of the histological features along the course of the facial vein of the desert camel (Camelus dromedarius): Relevance to brain cooling. Acta Morphol Neerl-Scand 1988/ 89:26:249-54.

12. Winquist RJ, Bevan JA. The effect of surgical sympathetic denervation upon the development of intrinsic myogenic tone and the alpha and beta adrenergic receptor-mediated responses of the rabbit facial vein. J Pharmacol Exp Ther. 1979;211:1-6.

13. Elkhawad AO, Al-Zaid NS, Bou-Resli MN. Facial vessels of desert camel (Camelus dromedarius): role in brain cooling. Am J Physiol. 1990;258:R602-7.

14. Shigei T, Ishikawa N, Ichikawa T, Tsuru H. Differences in the response of three embryologically distinct segments of the isolated canine posterior vena cava to vasoactive substances. Blood Vessels. 1978;15:157-69.

15. Attardi G. Demonstration in vivo and in vitro of peristaltic contractions in the portal vein of adult mammals (rodents). Nature. 1955;176:76-7.
16. Bevan JA. Selective action of diltiazem on cerebral vascular smooth muscle in the rabbit: antagonism of extrinsic but not intrinsic maintained tone. Am J Cardiol. 1982;49:519-24.

17. Ohhashi T, Azuma T, Sakaguchi M. Active and passive mechanical characteristics of bovine mesenteric lymphatics. Am J Physiol. 1980;239:H8895.

18. Chiba S, Tsukada M. Dominant vasodilator action of norepinephrine in isolated, non-preconstricted simian facial veins. Jpn J Pharmacol. 1990;53:267-70.

19. Tsuru H, Nakai S, Uchiyama T, Teranishi Y. Endothelium-independent relaxant effect of 5-hydroxytryptamine (5-HT) on the isolated rabbit facial vein. J Smooth Muscle Res. 1998:34:101-10.

20. Chiba S, Tsukada M. Predominant acetylcholine-induced vasoconstriction in isolated, perfused simian facial veins. Eur J Pharmacol. 1990;191:311-8.

21. Nakane T, Tsujimoto G, Hashimoto K, Chiba S. Beta adrenoceptors in the canine large coronary arteries: Beta-1 adrenoceptors predominate in vasodilation. J Pharmacol Exp Ther. 1988;245:936-43.

22. Ikomi F, Kawai Y, Ohhashi T. Beta-1 and beta-2 adrenoceptors mediate smooth muscle relaxation in bovine isolated mesenteric lymphatics. J Pharmacol Exp Ther. 1991;259:365-70.

23. Purdy RE, Stupecky GL, Coulombe PR. Further evidence for a homogeneous population of beta-1-adrenoceptors in bovine coronary artery. J Pharmacol Exp Ther. 1988:245:67-71.

24. Janssen LJ, Daniel EE. Classification of postjunctional beta adrenoceptors mediating relaxation of canine bronchi. J Pharmacol Exp Ther. 1991;256:670-6.

25. Igarashi T, Ikomi F, Ohhashi T. Electrical stimulation-induced $\alpha 1$ - and $\alpha 2-$ adrenoceptors-mediated contraction in isolated dog thoracic ducts. J Auton Nerv Syst. 1998;71:18-24.

26. McPherson GA, Bevan JA. Specialization in beta-1 and beta-2 adrenoceptor distribution in veins of the rabbit face: relationship to myogenic tone and sympathetic nerve innervation. J Pharmacol Exp Ther. 1987;240:99-105. 